\title{
MARKETING PESSOAL E ENFERMAGEM: PROJEÇÃO PARA VISIBILIDADE SOCIAL DO ENFERMEIRO
}

Josivaldo Barreto Andrade, Maria de Belém Cavalcante ${ }^{1}$, Maíra Rosa Apostólico ${ }^{1}$

Objetivo: conhecer a percepção dos enfermeiros sobre marketing pessoal e verificar como o utilizam em seu cotidiano de trabalho. Metodologia: estudo exploratório, descritivo, de abordagem qualitativa, que utilizou entrevistas semiestruturadas com 16 enfermeiros, submetidas à Análise de Conteúdo. Resultados: emergiram três categorias: Percepção sobre marketing profissional, Imagem pessoal e Projeção do ambiente organizacional. Várias estratégias foram utilizadas para potencializar o marketing pessoal, como imagem, aparência e postura ética, as quais contribuíram para a visibilidade da profissão. Conclusões: os profissionais reconheceram a importância de investir na própria imagem, como forma de valorizar a si mesmo e a profissão. Descritores: Marketing, Autoimagem, Papel Profissional, Enfermagem.

\section{PERSONAL MARKETING AND NURSING: PROJECTION FOR THE NURSE SOCIAL VISIBILITY}

Objective: to know the perception of nurses about personal marketing and verify how they use it in their daily work. Methodology: exploratory, descriptive qualitative approach study, that applied a semi-structured interview to 16 nurses, submitted to Content Analysis. Results: three categories were identified: Perception about professional marketing, Personal image and Projection of the organizational environment. Several strategies were used to improve the personal marketing, as image, appearance, and ethical posture, which contributed to the visibility of the profession. Conclusion: professionals recognized the importance of investing in their own image as a way to value themselves and the nursing profession.

Descriptors: Marketing, Self Concept, Professional Role, Nursing.

\section{SEGURIDAD DE LOS PACIENTES EN LA PERCEPCIÓN DE ENFERMEROS: UNA CUESTIÓN MULTIPROFESIONAL}

Objetivo: conocer la percepción de los enfermeros sobre el marketing personal y verificar cómo utilizan en su cotidiano de trabajo. Metodologia: estudio exploratorio, descriptivo con enfoque cualitativo, que utilizó entrevistas semiestructuradas con 16 enfermeras sometidas al Análisis de Contenido. Resultados: tres categorías surgieron: Percepción sobre marketing profesional, Imagen personal y Proyección del ambiente organizacional. Varias estrategias se utilizaron para mejorar la marketing personal como imagen, apariencia y postura ética, promoviendo visibilidad de la profesión. Conclusión: los profesionales reconocen la importancia de invertir en su propia imagen como forma de valorarse a sí mismos ya la profesión de enfermería.

Descriptores: Mercadeo, Autoimagen, Rol Professional, Enfermería. 


\section{INTRODUÇÃO}

A enfermagem profissional enfrenta desafios para superar preconceitos construídos pelo imaginário coletivo, influenciando a aceitação e o reconhecimento da autonomia profissional. A visibilidade da profissão está relacionada à sua trajetória histórica e à falta de cientificidade que, por muito tempo, resultou em comportamentos considerados inadequados e em falta de reconhecimento diante da equipe de saúde ${ }^{(1)}$. Entretanto, o mundo do trabalho e a influência nele exercida pelos meios de produção, pela tecnologia e pelas relações sociais imprimem, nos profissionais, a necessidade de diversificar suas qualidades para além das competências técnicas pertinentes à profissão. Assim, o modo como se comportam e se relacionam, sua visão de mundo e seus valores, sua capacidade empreendedora e versatilidade na condução e solução de conflitos são essenciais para o destaque em suas carreiras ${ }^{(2)}$

Nesse contexto, para além do conhecimento científico, o modo de agir, o compromisso e a satisfação com as atividades exercidas também promovem a visibilidade dos enfermeiros. Em muitas situações, a identidade profissional é construída e reforçada pelos meios de comunicação em massa, nem sempre resultando em reconhecimento positivo e em valorização do cuidar científico exercido pela enfermagem( ${ }^{(3)}$.

Estudo realizado com enfermeiros israelenses identificou tendência dos meios de comunicação em reforçar aspectos negativos da profissão, como casos de negligência e de sobrecarga de trabalho, configurando um grande desafio para o recrutamento de estudantes e futuros profissionais ${ }^{(4)}$

Nesse sentido, o marketing pessoal tem como objetivo divulgar as capacidades e as potencialidades das pessoas, atraindo e mantendo relacionamentos permanentes nos âmbitos pessoal e profissional, além da satisfação de todos os envolvidos. Ele requer planejamento, bem como a utilização de estratégias para o alcance de uma vantagem competitiva ${ }^{(5)}$.

O marketing pessoal, juntamente à qualificação e às competências, constituem os pilares de um promissor futuro profissional. Qualificação e competências funcionam como indicadoras das limitações e potencialidades pessoais que devem ter destaque pelas estratégias de marketing pessoal. As três dimensões devem ser trabalhadas contínua e conjuntamente, construindo uma visão estratégica, além de objetivos de crescimento e desenvolvimento pessoal e profissional. Para tal, utilizam-se a comunicação interpessoal, as redes de relacionamentos, o espírito de equipe, a visão estratégica, a liderança, entre outros. Não se trata de criar um personagem profissional fictício, mas de valorizar potencialidades individuais, para consolidar uma imagem favorável ao crescimento de cada um e da instituição onde $\operatorname{atua}^{(6)}$
Considerando o contexto histórico da enfermagem e os desafios enfrentados pelos profissionais para a construção de sua imagem pessoal, o presente estudo indagou se os conhecimentos dos profissionais sobre o marketing pessoal são aplicados em estratégias efetivas para a promoção de uma autoimagem positiva e empreendedora. Para tanto, o objetivo da investigação foi conhecer a percepção dos enfermeiros sobre marketing pessoal e verificar como o utilizam em seu cotidiano de trabalho.

A finalidade desse estudo foi explicitar como o profissional pode potencializar a valorização de sua imagem profissional, por meio de estratégias de marketing pessoal, muitas vezes utilizadas, mas sem a devida intencionalidade. Ressalta-se a escassez de estudos nessa temática nas bases de produção científica, o que justifica sua relevância.

\section{METODOLOGIA}

Pesquisa exploratória, descritiva, de abordagem qualitativa, desenvolvida em um hospital privado da Zona Sul do município de São Paulo, que, na ocasião da coleta de dados, contava com um contingente de 116 enfermeiros, 225 técnicos de enfermagem e 248 auxiliares de enfermagem.

O convite para participar do estudo ocorreu nas várias clínicas da instituição e nos diversos períodos de trabalho, incluindo fins de semana, para todos os enfermeiros em atividade. O critério de inclusão foi atuar na instituição há mais de seis meses. Foram excluidos profissionais que estivessem gozando férias, em processo de aposentadoria ou afastados por qualquer motivo durante o periodo das entrevistas. Voluntariaram-se 16 profissionais, que atenderam aos critérios de inclusão, constituindo-se nos participantes deste estudo. As entrevistas foram agendadas em horários convenientes aos participantes, solicitando-se autorização para gravação do conteúdo em mídia digital.

A coleta de dados foi realizada por meio de entrevista semiestruturada, com roteiro elaborado para este estudo, entre os meses de maio e junho de 2014, gravadas e, posteriormente, transcritas para análise. As questões norteadoras versaram sobre o significado de marketing, estratégias para potencialização ou promoção do marketing pessoal e suas implicações. A coleta de dados foi finalizada quando foi identificada a saturação dos dados, conforme previsto no método qualitativo de pesquisa. As entrevistas foram codificadas utilizando-se nomes de flores para identificação dos entrevistados, resguardando-se o anonimato.

Aanálise das entrevistas apoiou-sena técnica de Análise de Conteúdo, seguindo as três etapas preconizadas pelo método: pré-análise, exploração e tratamento dos resultados ${ }^{(7)}$. Foi elaborado um instrumento com duas colunas; na primeira, 
foram dispostas as falas dos participantes na integra; na segunda, foram selecionadas as unidades de significados, buscando elementos relacionados à questão norteadora do estudo. Posteriormente, essas unidades de significados foram agrupadas em temas que constituíram as categorias desta investigação.

A pesquisa foi aprovada pelo Comitê de Ética e Pesquisa da Universidade Guarulhos e autorizada pela instituição hospitalar, local do estudo, respeitando-se os preceitos éticos da pesquisa.

\section{RESULTADOS}

Dos 16 entrevistados, nove eram mulheres. A idade dos participantes variou entre 26 e 44 anos, com média de tempo de oito anos de formação, de sete anos de atuação como enfermeiros e seis anos de atuação na instituição. Os entrevistados trabalhavam em diversas áreas da assistência em enfermagem da instituição. Da análise do conteúdo, emergiram três categorias.

$\mathrm{Na}$ primeira categoria, Percepção sobre marketing, emergiu a percepção do enfermeiro sobre marketing profissional. O marketing, para os entrevistados, associouse à imagem do profissional diante das pessoas. Tratou-se da maneira de apresentar e divulgar, para os outros, seu produto, buscando confiança e conhecimento.

Marketing é uma divulgação de algum produto, é uma divulgação que você quer fazer em cima daquele produto, daquele material que você pretende inserir, você pretende estar no mercado de trabalho, então o marketing é uma propaganda daquilo que você tem para oferecer, tanto no caso de pessoas, pacientes. (Margarida)

Uma forma de promoção, uma forma de apresentar alguma coisa para outra pessoa, promover ou a si ou a algum produto. (Girassol)

$\mathrm{Na}$ segunda categoria, Imagem pessoal, os relatos apontaram para a importância da imagem que o profissional apresentava aos outros. No ambiente de trabalho, os aspectos relacionados ao comportamento e à boa apresentação pessoal foram considerados fundamentais. Foram destacadas a atenção que se devia adotar com relação às vestimentas, à maquiagem, à aparência dos cabelos, à barba, entre outras coisas.

Em relação à apresentação pessoal, os participantes acreditavam que ter uma boa aparência, vestir-se bem e estar com uma boa apresentação pessoal eram elementos necessários à obtenção de êxito e assertividade na imagem do enfermeiro. Houve referência à preocupação quanto à forma de se apresentar para o cliente, principalmente no primeiro contato, para que sua imagem pessoal tivesse um impacto positivo e gerasse uma percepção de otimismo no atendimento e no ambiente profissional.

Como eu sou enfermeira, o meu marketing pessoal é estar sempre uniformizada na instituição onde eu trabalho, saber falar com o cliente, olhar no olho, falar sobre os meus conhecimentos, o tempo que eu tenho na empresa, passar uma boa confiança para o cliente, isso para mim é marketing pessoal. (Dama-da-Noite)

A postura profissional foi associada com as atitudes, como a maneira de falar, agir, vestir-se, executar o trabalho e relacionar-se com as pessoas. Ter essa marca a seu favor foi considerada uma tarefa que exigiu paciência, disciplina, perseverança, determinação e um conjunto de crenças e valores que nortearam as atitudes.

Os meus valores eu agrego na minha postura com ética, profissionalismo, sigilo profissional, desempenho o meu atendimento com humanização. Isso eu agrego no meu marketing e tento buscar sempre o melhor de mim, para ser um profissional reconhecido no mercado de trabalho e pela minha equipe e pelos meus pacientes, o que eu tento fazer diariamente. (Margarida)

A terceira categoria foi a Projeção do ambiente organizacional. Nos relatos dessa categoria, destacouse a importância do ambiente organizacional como local essencial para que o marketing profissional pudesse ter maior visibilidade. O cuidado humanizado foi destacado como ferramenta para seu marketing pessoal. Trabalhar pela melhoria do atendimento passou pela humanização e incluiu saber informar, orientar, acompanhar e acolher.

Por meio de um bom atendimento, por meio de você lidar com o paciente e seu familiar de uma forma mais humana, entendendo aquele momento que eles passam, de sofrimento. Eu acho que trato de uma maneira bem humana, sempre visando ao paciente em primeiro lugar e me mostrando sempre solícito. Mostrando-me sempre um profissional capacitado, que está ali à disposição para estar ajudando em tudo o que for possivel sempre. (Bromélia)

A comunicação, em suas mais variadas formas, foi vista como estratégia imprescindivel, tanto no ambiente detrabalho, quanto na vida social do enfermeiro. Para os entrevistados, a prestação de um bom serviço e a comunicação foram as melhores maneiras de vender sua imagem profissional.

Falar, comunicar, sempre deixar à vista, mostrar realmente a necessidade, a importância do seu trabalho dentro do ambiente que você está. (Gérbera)

Os discursos retrataram a importância do papel do enfermeiro e a relevância do enfermeiro nas organizações de saúde, chamando a atenção para a permanência integral desse profissional nas instituições hospitalares e apontando os aspectos que dificultavam e facilitavam a visibilidade do profissional enfermeiro na sociedade como um todo. 
Eu acho que a classe precisa aprender a ser mais unida, ter mais respeito entre si mesmo e na sociedade, saber que a nossa profissão é muito importante como qualquer outra, mas aprender a se valorizar mesmo, tendo mais ética entre os profissionais e a sociedade enxergar o enfermeiro como alguém que é importante mesmo, porque o enfermeiro que fica nas 24 horas ali do lado do cliente. (Dama-da-Noite).

\section{DISCUSSÃO}

A análise das entrevistas realizadas com 16 participantes resultou em três categorias referentes à percepção do marketing e sua utilização no cotidiano de trabalho. A percepção dos entrevistados esteve de acordo com o conceito de marketing encontrado na literatura ${ }^{(8)}$, tido como disciplina funcionalista e ligada ao âmbito mercadológico das relações. Admite-se, porém, que as práticas de marketing influenciam na formação das personalidades e nas linguagens simbólicas presentes nas estruturas empresariais( ${ }^{(8)}$.

O marketing pessoal, atualmente, é uma importante ferramenta para a visibilidade, a colocação e a ascensão profissional(5), devendo-se considerar seu caráter político e os valores e significados sociais, que vendem juntamente com seu produto(9). Nessa perspectiva, o uso do conceito de marketing alcança mais do que a promoção e a visibilidade do produto, configurando-se como instrumento ideológico de criação de papéis e satisfação de necessidades.

A enfermagem lida com seres humanos em seus momentos de fragilidade, vulnerabilidade e sofrimento, constituindo o cuidado como uma identidade da profissão(10), o que requer do profissional alto grau de preparo e dedicação, além de uma elevada estima pessoal, profissionalização, conhecimentos, capacitação e independência. É necessário que o profissional encontre e demonstre satisfação no que faz, de forma a apresentar-se confiante em suas decisões e ações ${ }^{(11)}$.

Estudo brasileiro identificou que estudantes de enfermagem atribuem ao enfermeiro o papel de pessoa dedicada e responsável pela recuperação do paciente, necessitando do conhecimento científico e da postura ética ${ }^{(12)}$. Embora ainda que de forma tímida, a enfermagem tem usado o marketing para aumentar a visibilidade da profissão.
$\mathrm{Na}$ busca pela satisfação de seus clientes, atua por meios de comunicação, portfólio, estratégias de endomarketing e divulgação de conhecimentos científicos desenvolvidos ao longo dos anos de história da profissão(13)

O profissional enfermeiro ainda reconhece em si mesmo uma imagem ambígua de cuidador. Por um lado, representa o cuidado de enfermagem e seu saber científico. Por outro, está reduzido à concepção histórica do cuidado caritativo, vocacional e não profissional. Considerando que a formação da identidade profissional se faz por diferentes aspectos (autoimagem, heteroimagem e imagem da realidade), a imagem pessoal do enfermeiro é influenciada pela forma como ele percebe seu papel social e profissional, além de sua satisfação com o trabalho e imagem corporal(14-16).

Embora a humanização tenha sido citada pelos entrevistados como algo positivo, os obstáculos para sua incorporação nas atividades cotidianas podem prejudicar a imagem do profissional. Objeto de debates, o tema da humanização como parte integrante da política norteadora do Sistema Único de Saúde (SUS) afasta o cuidado do conceito de filantropia e caridade e o reposiciona no âmbito da prática científica. No campo da formação, a humanização deve ser tratada como tema transversal e obrigatório, não só nos aspectos relacionados à assistência, mas também na formação de uma conduta ética humanística, para cidadãos capazes de conviver e aprender com o outro(12).

Assim, não só os profissionais devem reconhecer a relevância de seu papel social. A qualidade dos serviços depende dos diferentes atores das equipes multiprofissionais e da organização do serviço. Um ambiente de trabalho que gera insatisfação nos profissionais certamente se reflete na percepção da qualidade de assistência ${ }^{(17)}$.

Outro fator importante na formação de vínculo entre o profissional e o paciente é a comunicação, destacada pelos entrevistados como potencializadora do marketing pessoal. A comunicação influencia no comportamento dos envolvidos e na maneira como eles se relacionam com o mundo. A postura comunicacional do profissional pode resultar em satisfação de pacientes, familiares e profissionais, como constatou estudo brasileiro realizado em unidade de terapia intensiva ${ }^{(18)}$.

Em relação ao ambiente organizacional, embora 
se percebam como referência dos serviços de saúde, demonstrando satisfação com o reconhecimento da comunidade de sua atuação em contextos de adversidade, enfermeiros sentem-se pouco valorizados pelos demais profissionais $^{(14)}$.

O trabalho da enfermagem encontra-se na interface entre os trabalhos em saúde. Embora tenha características que o diferencie das demais profissões, nem sempre os membros da equipe de enfermagem são diferenciados pela sociedade. Isso se reflete nas representações, na autoimagem, na valorização do trabalhador e no papel social que exerce, pontos que impactam na autonomia, no reconhecimento social e na (baixa) remuneração diante de longas jornadas de trabalho(14).

Uma estratégia para favorecer a visibilidade da profissão é o uso do marketing pessoal, com o propósito da "venda" de sua própria imagem de forma positiva, de acordo com as necessidades de seus clientes, da rede de relacionamento e das oportunidades do mercado(13-16)

Como limites do estudo, destacam-se a participação de enfermeiros de uma única instituição e o número reduzido de participantes, embora, para uma pesquisa de abordagem qualitativa, tenha sido satisfatório.

\section{CONCLUSÃO}

Os resultados deste estudo permitiram conhecer a percepção dos enfermeiros sobre marketing pessoal e verificar sua aplicabilidade em seu cotidiano de trabalho. Os profissionais de enfermagem estão preocupados com sua imagem, sua apresentação pessoal e sua projeção no ambiente de trabalho. Houve preocupação dos entrevistados em prestar um serviço com qualidade e, dessa forma, divulgar melhor a imagem do profissional de enfermagem.

Sugerem-se, como estudos de continuidade, pesquisas que desenvolvam e apliquem instrumentos ou escalas para verificar aspectos detalhados da construção da imagem profissional, além do desenvolvimento e utilização do marketing pessoal entre os enfermeiros.

\section{REFERÊNCIAS}

1. Martins MJ, Fernandes SJ. A visibilidade da enfermagem, dando voz à profissão: revisão integrativa. Rev Enferm UFPE On Line. 2014;8(1):2422-33.

2. Ferreira GE, Rozendo CA, Santos RM, Pinto EA, Costa AC, Porto AR. Caracteristicas empreendedoras do futuro enfermeiro. Cogitare Enferm. 2013;18(4):688-94.

3. Avila LI, Silveira RS, Lunardi VL, Fernandes GF, Mancia JR, Silveira JT. Implicações da visibilidade da enfermagem no exercício profissional. Rev Gaúcha Enferm. 2013:34(3):102-9.

4. Haron Y, Reicher S, Riba S. Factors influencing nursing career choices and choice of study program. Health Marketing Quarterly. 2014;31(2):167-77.

5. Lopes MR, Ribeiro PE, Cunha CA. Marketing pessoal e as redes sociais: ferramentas de colocação e ascensão profissional para recém-formados. Rev Caribeña de Ciencias Sociales. 2015;12.

6. Santos R. Contributos para a definição de uma visão estratégica na construção de um percurso profissional de sucesso. Sociologia. 2014:28:219-24.

7. Bardin L. Análise de conteúdo. São Paulo: Edições 70; 2016.

8. Kotler PA, Keller KL. Administração de marketing. 12. ed. São Paulo: Pearson; 2011

9. Gomes EE, Setton MG. Marketing e educação política: um estudo sobre agentes, estratégias e interpretações da cultura. Educ Real. 2016:41(3):85372 .

10. Oguisso T, Freitas GF. Cuidado - essência da identidade profissional de Enfermagem. Rev da Escola de Enferm da USP. 2016;50(2):188-9.

11. Chaves EC, Simão TP, Oliveira IS, Souza IP, Iunes DH, Nogueira
DA. Avaliação da autoestima em estudantes de enfermagem de uma universidade do sul de Minas Gerais (Brasil). Invest Educ Enferm. 2013:31(2):261-9.

12. Carvalho NM, Nery IS, Campelo V, Barbosa VR. O ensino da humanização no curso de bacharel em enfermagem numa universidade pública. Rev Enferm UFPE On Line. 2016:10(12):4554-62.

13. Mendes IA, Trevizan MA, Mazzo A, Godoy S, Ventura CA. Marketing profissional e visibilidade social na enfermagem: uma estratégia de valorização de recursos humanos. Texto Contexto Enferm. 2011:20(4):788-95.

14. Beck CL, Prestes FC, Tavares JP, Silva RM, ProchonowAG, Nonnenmacher CQ. Identidade profissional dos enfermeiros de serviço de saúde municipal. Cogitare Enferm. 2009:14(1):114-9.

15. Lucchesi LB, Mendes IA. Questionário multidimensional para análise da imagem do enfermeiro. Acta Paul Enferm. 2010:23(1):16-22.

16. Puggina AC, Cavalheiro AC, Trentino JP, Castro PF, Silva MJ. Relação entre necessidade de adornos com satisfação com imagem corporal $e$ autoconceito profissional da equipe de enfermagem. Escola Anna Nery [Internet]. 2015 [acesso em: 23 fev 2017];19(4):5563-70. Disponivel em: http://www.scielo.br/pdf/ean/v19n4/1414-8145-ean-19-04-0563.pdf

17. Araujo CA. O profissional da enfermagem e a criação de valores na saúde. Acta Paulista Enferm [Internet]. 2016 [acesso em: 7 mar 2017];29(4):3-4. Disponivel em: http://www.scielo.br/scielo.php?script=sci arttextEpid=SO103-21002016000400003\&lng=esEnrm=iso

18. Puggina AC, Ienne A, Carbonari KF, Parejo LS, Sapatini TF, Silva MJ. Percepção da comunicação, satisfação e necessidades dos familiares em Unidade de Terapia Intensiva. Esc. Anna Nery [Internet]. 2014 [acesso em: 23 fev 2017];18(2):277-83. Disponivel em: http://www.redalyc.org/ pdf/1277/127730686014.pdf 